\title{
FÉ E CIÊNCIA: UM DIÁLOGO INTERDISCIPLINAR SOBRE O ABORTO, A PARTIR DAS CONTRIBUIÇÕES DA RELIGIÃO E DA BIOÉTICA
}

\author{
FAITH AND SCIENCE: AN INTERDISCIPLINARY DIALOGUE ABOUT \\ ABORTION, FROM THE CONTRIBUTIONS OF RELIGION AND BIOETHICS
}

\author{
Antônio Sérgio Mendes Bezerra ${ }^{1}$
}

RESUMO: O presente trabalho tem como objetivo fazer uma abordagem sobre o aborto a partir da interdisciplinaridade entre fé e ciência; isto é, tecer uma reflexão a partir de contribuições da teologia e da bioética. Para isso, adotou-se a metodologia revisão bibliográfica. Essa perspectiva de trabalho e o modelo de metodologia ajudou a constatar a necessidade de se superar o isolamento das ciências em relação à teologia, e vice-versa. Ou seja, há uma necessidade de se fomentar o diálogo a partir dos avanços científicos e das teorias da interdependência destes saberes. Além disso, o artigo faz uma leitura das causas do aborto no Brasil e sinaliza aspectos determinantes a esse problema de saúde pública e que tem, em seu bojo, fatores que levam a essa prática abortiva no Brasil e em outros países do mundo. Por fim, baseado nos achados ao longo desse trabalho, apresenta-se uma reflexão acerca dos valores inerentes à dignidade da pessoa humana desde a concepção e por todo o ciclo de vida.

Palavras chaves: Fé. Ciência. Interdisciplinaridade. Teologia. Bioética. Aborto.

ABSTRACT: This paper aims to approach abortion based on the interdisciplinarity between faith and science; that is, to make a reflection based on contributions from theology and bioethics. For this, the bibliographic review methodology was adopted. This work perspective and the methodology model helped to confirm the need to overcome the isolation of the sciences in relation to theology, and vice versa. In other words, there is a need to foster dialogue based on scientific advances and theories of the interdependence of this knowledge. In addition, the article makes a reading of the causes of abortion in Brazil and points out determinant aspects to this public health problem and that has, in its core, factors that lead to this abortion practice in Brazil and in other countries of the world. Finally, based on the findings throughout this work, a reflection is presented about the values inherent to the dignity of the human person from conception and throughout the life cycle.

Keywords: Faith. Science. Interdisciplinarity. Theology. Bioethics. Abortion.

\section{INTRODUÇÃO}

Tomando em consideração alguns fatores tais como a difusão do conhecimento no contexto atual, as mudanças do mundo globalizado, os avanços tecnológicos que se propagam

\footnotetext{
${ }^{1}$ Especialização em Ecologia e Monitoramento Ambiental pela Universidade de Araraquara, UNIARA, Brasil. Graduação em Teologia pela Claretiano Centro Universitário, Claretiano/BAT, Brasil e em Pedagogia com Habilitação em Biologia- Universidade Estadual Vale do Acaraú, UVA-CE, Brasil. Email: bio.teos@gmail.com.
} 
com tanta rapidez, o acesso às informações que chegam aos leitores de modo compartilhado, e a quase ausência de limites entre as ciências e outros saberes; o presente projeto de pesquisa que tem como foco principal propor uma reflexão entre "Fé e Ciência: um diálogo interdisciplinar sobre o aborto a partir das contribuições da Religião e da Bioética”. Essa temática, que versa sobre a problemática da prática do aborto, é hoje um assunto polêmico. Assim, esse trabalho objetiva trazer uma contribuição para esse debate; ou seja, uma revisão de paradigma sem abrir mão dos valores fundamentais inerente ao ser humano e a proteção à vida.

A interdisciplinaridade, frente a fragmentação do conhecimento, nos impõe uma relação de aproximação, de incentivos através dos diversos saberes que vão se constituído em fenômenos desafiadores, mas, estimulantes que nos permite dialogarmos com conhecimentos diversos numa rede integrada que perpassa por áreas tão diferentes. No entanto, essa "diferença" é capaz de interligar informações e saberes que dialogam entre si com tanta precisão e profundidade que somos desafiados a entender o fenômeno das interdisciplinaridades dos saberes, ou permanecermos indiferentes, solitários a expansão do que o conhecimento a que a "razão" nos permite alcançar.

Para sustentar a proposta, remete-se ao diálogo entre o pensamento - Joseph Ratzinger e o do teólogo luterano Jürgen Moltmann, em vistas do alargamento da razão nos ambientes acadêmicos contemporâneos". Ratzinger propõe recuperar a unidade do saber para alargar e enriquecer o conhecimento. Jürgen Moltmann reivindica superar a separação entre teologia e ciências, fruto do advento da modernidade. Ambos insistem na importância de uma revisão do lugar da teologia na universidade atual, revisando a relação de diálogo entre teologia e ciências, numa perspectiva interdisciplinar. Pretende-se, portanto, estimular a relação entre teoria, vida, reflexão do teólogo e a práxis do cientista, metodologia essa já defendida e integrada aos assuntos pertinentes aos temas transversais no Currículo escolar. Contribuindo assim, na ressignificação do ser humano perante as relações sociais e com o meio no atual momento das discussões sobre o sentido da "vida", e nossa existência. (BRUSTOLIN, 2014).

Compreender, portanto, o diálogo entre a teologia e a ciência, é mergulhar na diversidade e complexidade das realidades humanas que possibilitam às pessoas uma grande variedade de sentidos para a vida. ${ }^{2}$ Hoje esta diversidade é cada vez mais percebida, tanto no sentido da diversidade cultural e religiosa, como da complexidade das diversas áreas do conhecimento humano. Para que a diversidade seja vista como uma riqueza, no entanto, é necessário que as pessoas estejam abertas para a existência de valores diferentes dos seus. Isto implica na necessidade de dialogar com a diversidade cultural e religiosa, bem como, com os 
diversos ramos do saber humano, com o objetivo de aprofundar a nossa visão de mundo e adequá-la a novas descobertas e conquistas humanas. Essa atitude é fundamental no diálogo entre religião e ciência, mais especificamente, entre a teologia e as ciências da natureza, entre o saber desenvolvido na academia e outros saberes humanos. No contexto da bioética, este respeito à diversidade e consciência da complexidade da realidade está sempre presente.

A sociedade contemporânea marcada pelo avanço constante da técnociência e biotecnologia, a bioética, assume o papel essencial na defesa dos vários desafios sociais, científicos, políticos e éticos no contexto atual. A humanidade vivencia novas situações, problemas, indefinições e soluções em diversos setores da vida. Ganhou visibilidade a ideia de que precisamos repensar nossa cidadania. Urge que definamos com maior precisão qual futuro nos interessa, considerando as mudanças ocorridas na sociedade.

Sair em defesa da vida no contexto pós-moderno de pensamentos relativistas, quase sempre somos interpretados como moralistas e injustos frentes as inúmeras necessidades e, sobretudo, de ordem patológica ou de saúde pública que hoje o povo enfrenta. Uma problemática que avança no contexto atual é a prática do aborto. Vejamos as definições a seguir:

O aborto é a supressão da vida do embrião humano antes do nascimento, podendo ser espontâneo ou provocado. Dentre todos os crimes que o ser humano poder praticar contra a vida, o aborto provocado ou induzido, aquele que acontece pela intervenção especial do ser humano, apresenta características que o tornam particularmente grave e abjurável. O Concílio Vaticano II, na Gaudium et spes, condena o aborto e defende a vida "a partir da concepção" e a Evangelium vitae define-o, juntamente com o infanticídio, como "crime abominável", entendendo-o como morte deliberada e direta, independentemente da forma como venha realizada, de um ser humano, na fase inicial da sua existência, que vai da concepção ao nascimento, (Gaudium et spes e Evangelium vitae, ( $\mathrm{nn} .27$ e 51; n. 58, apud conforme citado por (BENTO, 2014, p. 142).Concordando com BENTO3 (2014, p. I42), como a ciência biológica define a gravidez: "é o estado biológico da mulher desde o momento da concepção até o nascimento".

É Através de uma leitura dos debates sobre a problemática atual entorno do aborto, que hoje no Brasil, tramita nos poderes projetos para legalizá-lo ou avançar com leis de exclusão a vida humana, por considerar o problema apenas de saúde publica e não tratá-lo também como ético. Por isso, enquanto não encaramos com seriedade apontando soluções efetivas e plausíveis a dignidade humana, infelizmente, vai-se convivendo com esses números de abortos alarmantes no Brasil.

\footnotetext{
${ }^{3}$ A palavra aborto vem do latim abortus e significa expulsar prematuramente do útero feminino o nascituro, viável ou não, o que é a privação de nascimento, porque vem de ab, que quer dizer privação, e ortus, nascimento. (BENTO, 20I4, p. I4I).
} 
É elevado o número de abortos provocados anualmente. As pesquisas públicas apontam que, no âmbito mundial, cerca de 150 mil mulheres morrem anualmente por práticas de abortos clandestinos, incompletos.

No Brasil, a média de morte materna é de 156 mulheres para cada cem mil nascimentos. O aborto é considerado uma das principais causas de mortalidade materna. (BENTO, 2014, p. 142 e I43).

O contexto atual, marcado pelo o ateísmo crescente, nos faz sentirmos, desafiados a partida de uma reflexão sobre fé e ciência, de modo que, possamos fazer uma abordagem interdisciplinar, levantar uma discursão sobre os fatores geradores que levam a pratica do aborto e finalmente, contribuir com uma reflexão bioética em defesa do direito à vida.

Portanto, a fundamentação da pesquisa como revisão bibliográfica e com sustentação pelos estudiosos da bioética, se insere não somente nas hipóteses das interdisciplinaridades dos saberes, mas, sobretudo, nas questões do aborto com base nas contribuições da fé e da bioética.

A busca pela sensibilização e consequente a conscientização do respeito à vida é hoje um grande desafio para bioética em nosso país. É de relevância a reflexão sobre as questões que envolvem a bioética, como o aborto. $\mathrm{O}$ presente projeto de pesquisa tem por objetivo, responder a três indagações sem a pretensão de querer esgotar o problema aqui levantado. Primeiramente, relacionar fé e ciência a partir de uma abordagem interdisciplinar; em segundo lugar, relatar os fatores geradores que levam a prática do aborto e por ultimo, contribuir com uma reflexão bioética em defesa do direito à vida.

O projeto de pesquisa sobre bioética, portanto, tem como função trazer à tona a consciência de que o compromisso com a vida é mais do que uma atividade intelectual, é um dever ético a ser exercido por todos, posto que urge nos tempos atuais, como asseveram estudiosos de várias áreas das ciências, dentre elas a bioética, assumirmos um compromisso com a totalidade dos saberes no desafio a proteção e defesa a vida.

\footnotetext{
A bioética não pode mais ser entendida como um campo de saber específico, especializado, pois o seu referencial teórico e a sua prática situam-se na interseção da Medicina, da Biologia, da Ética e da Moral, do Direito, da Filosofia, e da Teologia e de todas as ciências humanas (SEHNEM, 2013, p.54).
}

Outro ponto crucial do TCC em pauta é estabelecer relações cada vez mais estreitas entre o "Logos" e a multidisciplinaridade, interdisciplinaridade com a teologia, sem isolamento ou superioridade unilateral, mas, apenas com o propósito da prática coerente das ciências para a promoção efetiva do respeito à cidadania de cada ser vivo que existe no planeta.

Portanto, a pesquisa em andamento tem por objetivo, contribuir com a sociedade e ao mesmo tempo, fomentar uma lógica do respeito ao ser humano, a partir da "concepção ao seu nascimento". Sem esgotar qualquer possibilidade do diálogo entre outras pessoas que pense 
diferentes ou de qualquer concepção religiosa, mas, sobretudo, estar aberta a diversidades de ideias e principalmente aquelas que trazem em seu bojo ações que promova a vida.

\section{CAPÍTULO I - FÉ E CIÊNCIA UMA ABORDAGEM INTERDISCIPLINAR}

\section{I.I Um olhar no contexto histórico}

O diálogo entre fée e ciência deve ser posto a partir de uma abordagem histórica, com o propósito crítico das dimensões que se insere nesse contexto. Haja vista a complexidade do contexto histórico que se dá tais fatos.

Iniciemos falando sobre as religiões milenares: O Judaísmo, o Islamismo e o Cristianismo. São religiões históricas que cresceram e se estabeleceram em diversas partes do mundo. Os seus seguidores pautavam sua vida numa doutrina, com suas tradições, símbolos, valores e princípios que cada uma a pregoava como forma de se relacionar com Deus.

Entre essas religiões, com abordagem no Cristianismo, tornaram-se instituições sólidas, de grande expressão, porque não dizer, poderosas. Portadoras de uma identidade própria, com normas e leis e por sua vez defendem o que é correto e errado, além de determinar comportamentos éticos e morais.

Uma visão teocêntrica prevaleceu num período da história, conhecida como Idade Media ou Idade das Trevas como era chamada pelos renascentistas, de tal forma que tudo girava em torno da Igreja, que estava no centro do povoado, no local mais alto com um sino em sua torre e dela dependia a vida das pessoas ao despertar, para rezar, ir às missas, além disso, tinha como finalidade de avisar contra as possíveis invasões ou saques. Tudo estava em torno da Igreja como um poder centralizador ${ }^{5}$ ela determinava normas e leis, e esperava dos seus fieis o comprimento das mesmas.

Segundo SEHNEM (2013), a oposição às religiões sempre foi um fato, através de rupturas, críticas e oposição aos dogmas, normas estabelecidas sem que se pudesse ser questionada ou discutido. Por isso, a santa inquisição, fogueiras, masmorras, torturas e confiscos de bens a quem não comungasse com o corpo doutrinário da igreja. Esse contexto histórico vai ser superado com as ideias renascentistas de volta as origens do pensamento clássicos da Grécia, com a perspectiva de trazer uma nova concepção holística de mundo e alimentar o antropocentrismo.

\footnotetext{
${ }^{4}$ Ora, a fé é o firme fundamento das coisas que se esperam, e a prova das coisas que se não veem $5 \mathrm{O}$ conceito de interdisciplinaridade fica mais claro quando se considera o fato trivial de que todo conhecimento mantém um diálogo permanente como Os outros conhecimentos, que pode ser de questionamento, de confirmação, de complementação, de negação, de ampliação, [...] (FORTES apud BRASIL 1999, p.88).
} 
Todavia, o ocidente do século XV e XVI, passa por rupturas e avanços entre o mundo velho o presente. Descobertas cientificas, globalização, introdução das ideias do filósofo Renée Descartes, "discurso sobre método" (1637) entre outros, como filósofo político Niccolo Maquiavel que escreveu O Príncipe (1513-1527) e a Arte da Guerra, por volta de (I519- 1520). O teocentrismo vai ficando de lado e agora a nova ordem é o antropocentrismo, negócios, lucros, exploração da natureza e do homem.

A relação entre a Ciência e a Religião é conflitante, fundamentalmente, pelo fato de ambas adotarem metodologias diferenciadas e especificas: uma tem como ponto de partida a crença no Deus e em valores sobrenaturais, sendo subjetiva, pessoal e íntima; em contrapartida, a Ciência é racional, objetiva, rigorosa, mensurável devendo apresentar uma farta documentação comprobatória. Podemos entender a racionalidade cientifica como conhecimento dos limites, e a racionalidade teológica como aquela que se encontra com ela num plano mais profundo da intencionalidade última e da responsabilidade ética em todos os níveis: pessoal, histórico, social e ecológico. Assim a teologia é capaz de dialogar com as ciências e a filosofia, mantendo, cada uma nas áreas do conhecimento, a sua especificidade. (SEHNEM, 2013, p.93 e 94).

Portanto, através desse simplório relato histórico, podemos compreender como o saber estava centralizado em uma única visão, "a transcendental", ou seja, o mundo enxergava apenas pelo um olho e respirava pelo um único pulmão. Neste contexto, surge uma Nava epistemologia para contrapor e equilibrar os saberes, embora isoladamente, a concepção antológica é dada ênfase e com isso, os negócios, a exploração e, sobretudo o lucro, estabelece um novo paradigma mundial com base na razão e nas ideias positivistas.

\section{I.2 Conflitante: Ciência e Religião}

Os conflitos entre a Religião e a Ciência, são levados em consideração por BARBOUR, através de duas dimensões: "o materialismo científico de um lado, e o literalismo bíblico do outro". Quando esse conflito é compreendido a partir de uma ótica do isolamento e, não numa concepção de especificidade dos saberes e da contribuição que cada conhecimento na sua essência pode favorecer, a um novo paradigma epistemológico, o dialogo fica inviável e impossível, pois ambos os conhecimentos se afirmam detentores da verdade, descartando uma unidade que expresse a singularidade do saber.

Vejamos como os estudiosos avaliam e explicam essa aproximação da Religião e a Ciência:

IAN G. Barbour é Professor emérito de Física e Religião no Carleton College em Northfiel, no Estado de Minnesota, e escreveu o livro Quando a ciência encontra a religião: inimigas, estranhas ou parceiras?. Nesse livro, o autor classifica a grande variedade de maneiras que os estudiosos 
relacionam a ciência e religião, divide-as em quatro etapas: a fase de conflito, a fase da independência, a fase de dialogo e a fase de integração.

I) Primeira fase - conflito: a relação da religião com a Ciência, no período histórico dos séculos I8 e 19, pode ser descrita como difícil, antagônica, conflitante e excludente.

2) Segunda fase - independência: a partir do fim do século ig e inicio do século 20 , vão sendo criadas concepções de autonomia, de independência em termos teórico-metodológicos sobre a Ciência e a religião.

3) Terceira fase - dialogo: mais ou menos na metade do século 20, iniciase a construção de um novo paradigma, no qual a concepção mecanicista vai cedendo lugar a uma visão holística da realidade, adotando-se o método interdisciplinar, inclusive entre a Ciência e a religião.

4) Quarta fase - integração: as décadas de 196o e de 1970 geraram uma serie de movimentos sociais que buscam uma mesma direção e convergência. (SEHNEM, 2013, p.94 apud BARBOUR, p. 2004).

Com base nessa divisão e sistemática dos saberes, vão sendo superado o isolamento e as dificuldades de entendimento, haja vista, a reflexão inerente às questões especifica relacionada a cada um dos sabres, com isso, vivemos novos paradigmas onde cada saber pode contribuir para o outro com a perspectiva de abrangência para o todo.

Concordando com SANCHES (2007 p. 13 apud ELLIS): um professor de matemática aplicada da Universidade de Cape Town afirma:

Ciência forma uma parte importante da vida humana, mas não é a base inteira da vida. Nós precisaremos sempre de estudar e ensinar ética, estética, filosofia, bem como ciência, e isto inclui religião, se você quer um ser humano completo. Aqueles que afirmam que ciência vai suplantar todos os outros saberes estão promovendo uma fantasia. "Seja gentil com eles, mas não os levem a sério".

Todavia, o conflito entre as diversas áreas dos saberes, sobretudo, entre Religião e Ciência, no contexto secularizado, tem avançado, porém, existe uma visão relativista, que afirma que as verdades universais são subjetivas, com isso, cria-se, uma confusão pondo e incentivando as verdades que cada um interpreta e que as convém. "O parcelamento e a compartimentação dos saberes impedem aprender o que está tecido junto". (FORTES 2012 p.3 apud MORIN 200o, p.45).

Tudo está interligado numa harmonia perfeita e todo conhecimento produzido até aqui, em qualquer área do saber, contribui para a superação do distanciamento da Fé e Ciência e desagua no mesmo rio, que se chama conhecimento, e tem como função servir aos seres vivos numa harmonia Planetária. 


\section{I.3 Teologia e bioética: um diálogo possível}

Segundo BRUSTOLIN (2014), não existe uma única teoria sobre interdisciplinaridade, mas, nos últimos 40 anos, evoluiu a necessidade de sua aplicabilidade. Desde 1970 busca-se uma construção epistemológica com explicitação filosófica para uma melhor definição. Na década de 1980, delimitavam-se as contradições epistemológicas dessa construção a partir de diretrizes sociológicas. Nos anos 1990, empreendia-se uma nova epistemologia com acento mais antropológico.

No Brasil foi Japiassu o primeiro estudioso a se ocupar com a temática. Para ele, a "interdisciplinaridade caracteriza-se pela intensidade das trocas entre os especialistas e pelo grau de interação real das disciplinas no interior de um mesmo projeto de pesquisa". Sabe-se que há uma interdependência das diversas áreas do conhecimento, para que um objeto ou realidade seja acessível. O isolamento, nesse caso, não é só um empobrecimento, mas uma deficiência no próprio ato de conhecer.

Essa relação entre teologia e bioética se insere na interdisciplinaridade: primeiramente a teologia que se ocupa de outras disciplinas para explicitar metodologicamente a revelação numa linguagem acessível e humana. Para BRUSTOLIN (2014 p.265), "A encarnação do Verbo expressa que entre Deus e o mundo existe uma infinita vizinhança e uma infinita distinção.

O Verbo humanado revela e respeita a autonomia do mundo, justamente enquanto se revela para indicar a destinação última do humano e do cosmo.” A teologia cristã surge na inter, multi e transcultural, ou seja, a teologia está encarnada na vida, e na realidade do "ser". Em segundo lugar, a bioética que nasce de reflexões sobre a medicina, médicos, instituições hospitalares, que possa traçar um perfil ético de respeito a dignidade da pessoa humana, como também os teólogos, para que possa mostrar a vivência religiosa como pressuposto de esperança e sentido da existência. (SANCHES, 2012, p.Io).

Portanto, o diálogo entre teologia e bioética, nasce da interdisciplinaridade do sentido da existência e da capacidade de reflexão em função da pessoa humana com o intuito da defesa a vida na sua plenitude.

\section{CAPÍTULO II - OS FATORES GERADORES QUE LEVAM A PRÁTICA DO ABORTO}

\section{I A adolescência: sexualidade precoce}

A adolescência caracteriza-se, pelo período de transformações biológicas, conhecimento de si, e, sobretudo, a aceitação dessas etapas entre a infância e a vida adulta; 
marcada, muitas vezes, por conflitos relacionados à puberdade, o olhar-se como diferente, a explosão hormonal e o despertar da sexualidade.

Urge a necessidade de estabelecer uma cultura de informação a respeito da sexualidade na adolescência, que ainda é considerado tabu por muitos e, principalmente pela "família", que deveria ser a primeira a informar, aconselhar, no entanto, transfere tudo para a escola apostando na capacidade de solução integral da formação do caráter e do ser como tal.

A gravidez durante a adolescência recebeu da sociedade considerável atenção na metade e no final dos anos 70 (Ziegel 1985). Sabe-se que é considerada como um problema de Saúde Pública no Brasil como também em outros países. A situação vem agravando-se a cada dia, pois muitas vezes tem como consequência a prática do aborto, que constitui-se em uma das principais causas de morbi-mortalidade relacionadas à gravidez na adolescência.

Só no ano de 1998, mais de 50 mil adolescentes foram atendidas em hospitais públicos para submeterem a curetagem pós-aborto, sendo que cerca de 3 mil foram realizadas entre jovens com idade entre ro e I4 anos( BRAGA et al, 2008 p.77 apud Brasil 1999).

Os dados mostram que o problema é sério, porém, o desafio de preparar essa geração de adolescentes para enfrentarem o mundo real, não pode está restrita somente as medidas do poder público, mas de toda a sociedade tendo como referência a família e consequentemente a escola, igrejas e outras instituições atuantes e compromissadas com a causa, que possam atuar de modo incisivo em busca de solução e de uma nova mentalidade ativa para erradicar essa patologia ou simplesmente contemplarmos de maneira passiva aos números que crescem lamentavelmente.

\subsection{Os principais fatores geradores do aborto}

Conforme (BENTO, 2008, p.I42), uma gravidez caracteriza-se pelo o estado de gestação biológica da mulher a partir da fecundação ao parto. Atualmente empregam conceitos, contrariando o rigor científico que aponta para o inicio da vida a partir da nidação.

O aborto é a supressão da vida do embrião humano antes do nascimento, podendo ser espontâneo ou provocado. Dentre todos os crimes que o ser humano pode praticar contra a vida, o aborto provocado ou induzido, aquele que acontece pela intervenção especial do ser humano, apresenta características que o tornam particularmente grave e abjurável. O Concilio Vaticano II, na Gaudium et spes, condena o aborto e defende a vida "a partir da concep̧̧ão" (BENTO, 2008, p. I4I, apud, nn. 27 e 5I).

Conforme BRAGA et al (2008), os fatores mais latentes que estão por traz da gravidez precoce é a prática da sexualidade iniciada antes de receberem uma formação sólida para enfrentarem uma vida sexualmente ativa, mas infelizmente, ainda falta a superação dos tabus 
que é uma realidade em muitos contextos familiares. Muitas vezes são influenciados por uma mídia globalizada que impõem determinados "modismos" entre adolescentes. Além disso, a carência de políticas públicas, diálogos entre pais e filhos, entretanto, não deve ser empecilhos para por em prática, posturas que incentive aos adolescentes a busca de informações seguras para minimizar é essa chaga da gravidez precoce e consequentemente do aborto, tão presente na população brasileira. "A realidade mostra que, no Brasil, $25 \%$ das famílias são mantidas por mulheres, ou seja: há muitas mulheres sozinhas sem companheiro, com filhos para criar. Esse é o nosso cotidiano, é o que vemos nas periferias das grandes cidades e nos lugares pobres do meio rural”. (BENTO, 2008, p.I43).

Alguns dados estatísticos sobre a realidade do aborto no Brasil:

Figura I - Número de Abortos Provocados por Região do País.

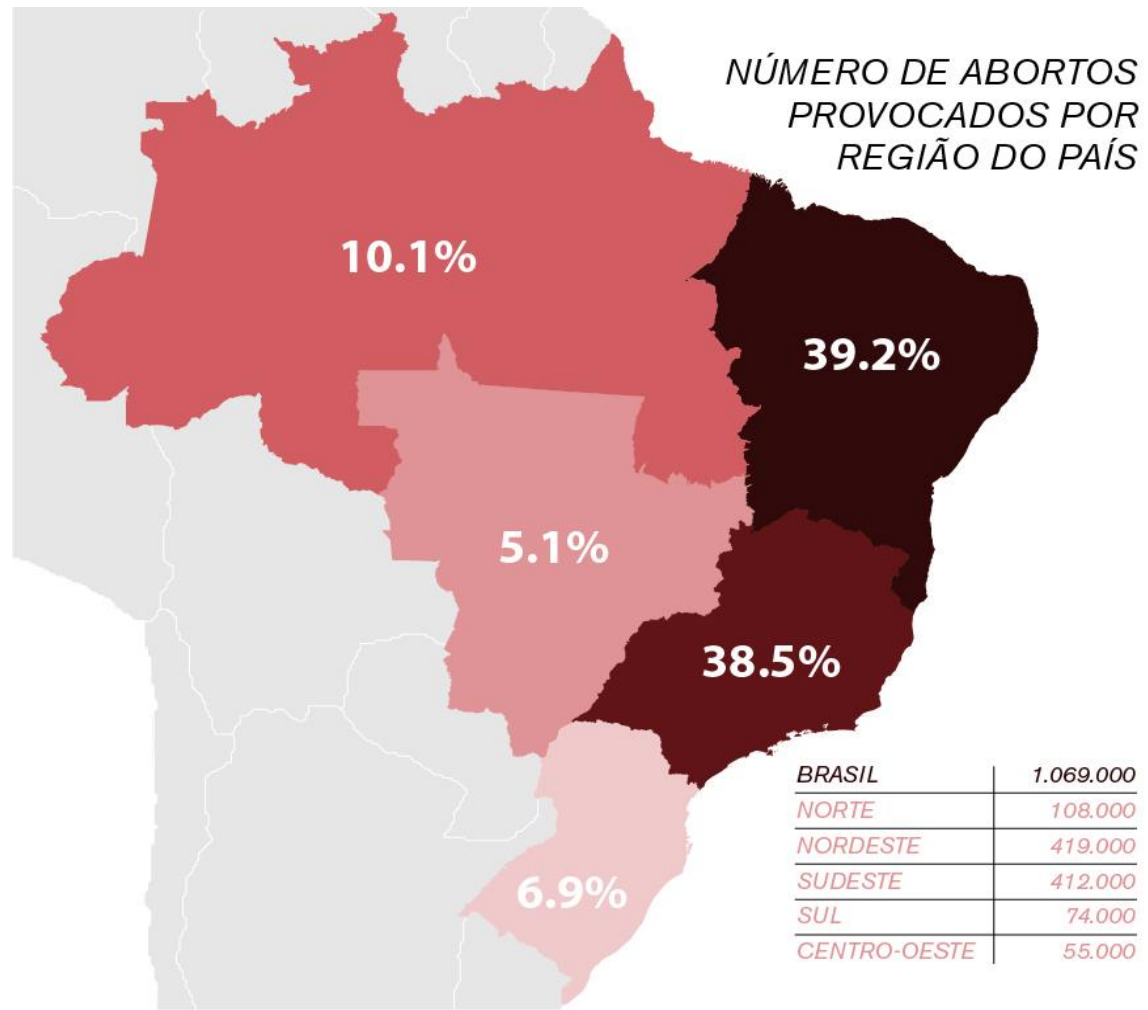

Fonte: Agência Patrícia Galvão. 
Figura 2 - Total de Mulheres que fizeram Aborto Provocado no Brasil, por nível de Escolaridade.

TOTAL DE MULHERES QUE FIZERAM ABORTO PROVOCADO NO BRASIL, POR NÍVEL DE ESCOLARIDADE

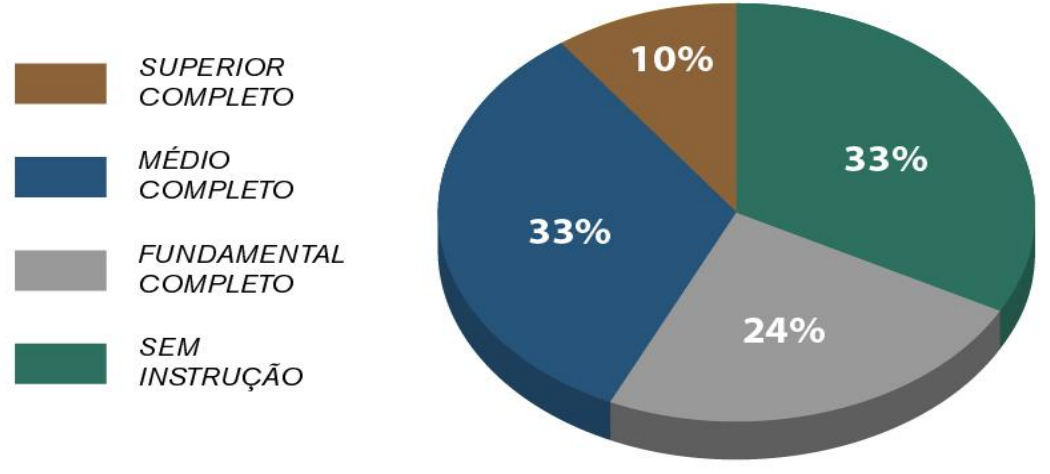

Fonte: Agência Patrícia Galvão

A prática do aborto passa por várias situações inerentes a questões sociais como: escolaridade, cor da pele, poder econômico, problemas familiares, equilíbrio emocional, e, sobretudo, a falta de informação.

\subsection{A lei brasileira sobre o aborto}

Segundo SEHNEM (2013), Podemos fazer uma leitura mundial e fragmentar em três blocos os países que permitem o aborto: no primeiro bloco, existe, entorno de 56 países que são a favor do aborto, estimando $40 \%$ da população mundial; no segundo bloco, estima-se 40 países que são a favor do aborto parcialmente; e, por último, no terceiro bloco de países, onde se encontra a maioria, dentre eles o Brasil, que ainda não permite a pratica do aborto, apenas com algumas restrições previsto em Lei (Código Penal). Esse mesmo Código Penal Brasileiro, prever nos artigos 124 a I27, que o aborto é considerado crime contra a vida.

\footnotetext{
A prática do aborto no Brasil é proibida por lei, exceto em duas situações: estupro e risco de vida da gestante. Porém, os hospitais não estão preparados para atender mulheres que se enquadrem em uma dessas situações. (BENTO, 2008 p.I42).
}

Todavia, está fundamentado em lei ainda o direto de nascer e de não atentarem contra vida, exceto, em dois casos já citado anteriormente que é o estrupo e risco de vida da gestante. Porém, existem muitos debates em torno da legalização do aborto no Brasil, no entanto, não existe felizmente uma aprovação por parte da população para a implantação do 
aborto, por varias questões éticas, morais, sociais, religiosas e principalmente pela convicção da defesa incondicional a favor da vida em qualquer circunstância.

\subsection{A posição cristã sobre o aborto}

Do ponto de vista da teologia cristã, a vida é um dom de Deus gratuito e livre para ser vivido na sua profundidade e essência. A vida é criada por Deus como nos relata a Sagrada Escritura, especificamente no livro do Gênesis que narra à criação da vida.

O Gênesis é uma coleção de lendas (Sagen) - uma narração poética, popular, transmitida desde antigamente, que versa sobre pessoas ou acontecimentos. (SANCHES, 2013, p.21 apud, LÓPEZ, 2004, p.39).

Dando continuidade LÓPEZ afirma que o Gênesis "é uma narração descritiva que se apoia em ideias e concepções mitológicas” (LÓPEZ, 2004, p. 68). A necessidade de busca por elementos que revele como a vida surgiu, será limitado por conta dos conhecimentos da biologia que ainda praticamente não existia como temos atualmente, portanto, as considerações a respeito de como a vida foi criada e, que tinha como base as concepções mitológicas, porém, não vamos esperar um debate que se ocupem dos conhecimentos das ciências biológicas moderna com toda sua abrangência. Numa leitura dos três primeiros capítulos do livro do Gênesis, podemos entender que se trata de relatos que mostra Deus como Criador, portanto, Ele é sua fonte criadora estabelece uma relação profunda com a humanidade.

Essa relação estabelecida pelo o relato da criação do ser humano é precedido por uma decisão de Deus ${ }^{6}$. Façamos o homem à nossa imagem e semelhança. ( $\mathrm{Gn}$ I, 26). Ao ser criado, o ser humano é concebido a imagem e semelhança de Deus. Isto é, para a tradição bíblica, um elemento diferencial e indicador de sua dignidade ímpar entre os outros seres criados. É este o fundamento bíblico da individualidade do ser humano, onde está implícito o respeito pelo ser humano, por que não dizer, desde seu estágio embrionário. Quando olhamos para a criação do ser humano criado desde o primeiro momento em que ele é formado. A dignidade está na força de decisão do verbo "façamos" e no substantivo "imagem", que "analogicamente significa a pessoa" (SANCHES, 2013, p.21, apud LÓPEZ, 2004, p.68).

Para SANCHES (2013), desde a Patrística, a Igreja é contra ao aborto e a favor da vida desde sua concepção. Pois, em Santo Agostinho, temos a obra sobre esse tema em De nuptiis et concupiscenti, onde responde a aqueles que o acusavam de ser seguidor do maniqueísmo. As afirmações de Santo Agostinho são fortes sobre o aborto. "Para ele os que praticam o aborto não podem ser considerados marido e mulher, mas amantes. Se apenas um

$6\{\ldots\}$ fui concebido como homem e - com o aborto - eu não existiria, como crianças que nunca viram a luz (Jó 3, 3. 16). 
é culpado, ou a mulher surge como prostituta ou o marido como adúltero". Outros teólogos, também se posicionaram a posteriori a esse tema.

Portanto, desde os primeiros séculos do cristianismo, as Igrejas de tradições cristãs se posicionaram e continuam mantendo a postura ética contra o aborto A prática do aborto passa por várias situações inerentes a questões sociais como: escolaridade, cor da pele, poder econômico, problemas familiares, equilíbrio emocional, e, sobretudo, a falta de informação.

\subsection{A lei brasileira sobre o aborto}

Segundo SEHNEM (2013), Podemos fazer uma leitura mundial e fragmentar em três blocos os países que permitem o aborto: no primeiro bloco, existe, entorno de 56 países que são a favor do aborto, estimando $40 \%$ da população mundial; no segundo bloco, estima-se 40 países que são a favor do aborto parcialmente; e, por último, no terceiro bloco de países, onde se encontra a maioria, dentre eles o Brasil, que ainda não permite a pratica do aborto, apenas com algumas restrições previsto em Lei (Código Penal). Esse mesmo Código Penal Brasileiro, prever nos artigos 124 a I27, que o aborto é considerado crime contra a vida.

Todavia, está fundamentado em lei ainda o direto de nascer e de não atentarem contra vida, exceto, em dois casos já citado anteriormente que é o estrupo e risco de vida da gestante. Porém, existem muitos debates em torno da legalização do aborto no Brasil, no entanto, não existe felizmente uma aprovação por parte da população para a implantação do aborto, por varias questões éticas, morais, sociais, religiosas e principalmente pela convicção da defesa incondicional a favor da vida em qualquer circunstância.

Do ponto de vista da teologia cristã, a vida é um dom de Deus gratuito e livre para ser vivido na sua profundidade e essência. A vida é criada por Deus como nos relata a Sagrada Escritura, especificamente no livro do Gênesis que narra à criação da vida.

Dando continuidade LÓPEZ afirma que o Gênesis "é uma narração descritiva que se apoia em ideias e concepções mitológicas" (LÓPEZ, 2004, p. 68). A necessidade de busca por elementos que revele como a vida surgiu, será limitado por conta dos conhecimentos da biologia que ainda praticamente não existia como temos atualmente, portanto, as considerações a respeito de como a vida foi criada e, que tinha como base as concepções mitológicas, porém, não vamos esperar um debate que se ocupem dos conhecimentos das ciências biológicas moderna com toda sua abrangência. Numa leitura dos três primeiros capítulos do livro do Gênesis, podemos entender que se trata de relatos que mostra Deus como Criador, portanto, Ele é sua fonte criadora estabelece uma relação profunda com a humanidade. 
Para SANCHES (2013), desde a Patrística, a Igreja é contra ao aborto e a favor da vida desde sua concepção. Pois, em Santo Agostinho, temos a obra sobre esse tema em De nuptiis et concupiscenti, onde responde a aqueles que o acusavam de ser seguidor do maniqueísmo. As afirmações de Santo Agostinho são fortes sobre o aborto. "Para ele os que praticam o aborto não podem ser considerados marido e mulher, mas amantes. Se apenas um é culpado, ou a mulher surge como prostituta ou o marido como adúltero". Outros teólogos, também se posicionaram a posteriori a esse tema e a favor da vida.

\section{CAPÍTULO III - UMA REFLEXÃO BIOÉTICA EM DEFESA DO DIREITO À VIDA}

\section{I O que é a bioética?}

Segundo BENTO (2008), a bioética não é uma nova disciplina sobre ética, mas uma parte da ética, e nessa perspectiva pode citar o conceito do Monsenhor Sgreccia: "A bioética é aquela parte da filosofia moral que considera a liberdade, ou menos, das invenções sobre a vida do ser humano e, particularmente, aqueles conexos com a prática e o desenvolvimento das ciências médicas biológicas”. Na mesma direção vai à definição oferecida por Uberto Scarpelli, segundo o qual a bioética é "a parte da ética que tem por objeto os atos humanos concernentes à vida física".

Para SEHNEM (2013), não podemos mais restringir o entendimento da bioética como um conhecimento especifico, pois existe uma relação teórico-prático com outras áreas como: a Medicina, Biologia, Ética, Moral, Direito, Filosofia e da Teologia e por sua vez se insere nas ciências humanas de um modo geral.

A Bioética tem sua origem, no inicio dos anos de 1970 nos EUA, com a explosão do conhecimento cientifico, especificamente no campo da medicina, com o uso de pesquisas e a utilização em seres humanos, e os dilemas da morte e como morrer com base na definição de morte encefálica, transplantes de órgãos, clonagens em animais, representaram avanços relevantes, mas suscitou interrogações éticas em todos os setores envolvidos com as pesquisas e a sociedade em geral.

Oncologista norte-americano Van Rensselaer Potter, que publicou um trabalho com o tema: Bioética: uma ponte para o futuro, no ano de 1971, isso, representou um fato histórico para essa área de conhecimento. Potter demonstrava uma preocupação com o planeta, e, sobretudo em dois campos: área ecológica e com o liberalismo cientifico. (SEHNEM, 2013, p.40 e 45$)$. 
Como vimos, a bioética é um saber que versa por várias áreas do conhecimento humano, tendo como foco principal a reflexão e análise das ações antropogênicas em relação aos valores éticos inerentes a vida no planeta e, sobretudo, a pessoa humana, ou seja, o seu estado físico-biológico.

\title{
3.2 A bioética e a causa da vida humana
}

A relação que se estabelece entre bioética e o aborto é a análise profunda sobre o tema, porém não é fácil abordar essa questão polêmica, pois é um problema da sociedade e a mesma carrega em seu bojo várias opiniões, e porque não dizer, até relativiza sem critérios humanizados o assunto, criando assim, obstáculos que dificultam o diálogo em seu entorno. Conforme os estudiosos da bioética argumentam que:

A problemática do aborto é um exemplo nítido tanto da dificuldade de se estabelecer diálogos sociais frente a posições morais distintas quanto do obstáculo em se criar um discurso acadêmico independente sobre a questão, uma vez que a paixão argumentativa é a tônica dos escritos sobre o mesmo. Para um não-iniciado, a maior dificuldade ao ser apresentado à literatura relativa ao aborto é discernir quais são os argumentos filosóficos e científicos consistentes dentre a infinidade de manipulações retóricas que visam apenas arrebatar multidões para o campo de batalha travado sobre o aborto. (DINIZ e ALMEIDA, 1998, p.125).

Muitos esforços foram feitos e continuam sendo, no intuito de compreendermos os aspectos envolvidos na prática do aborto no Brasil e em outros países, a partir das contribuições da bioética. Entretanto, não se deve esgotar essa temática de saúde publica que é o aborto, mas perseverar nessa árdua defesa a favor da vida. Na mesma perspectiva, Leocir Pessini reflete:

\begin{abstract}
Até muito recentemente, tanto o inicio da vida humano quanto o seu final escapavam por completo do nosso controle. Nascia por obra do acaso, da natureza, ou, então, "graças a Deus", e também se despedia da vida pelas mesmas razões. O conhecimento humano era muito pequeno em relação a esses processos. Hoje, essa realidade mudou e praticamente quase tudo passa pelo crivo da ação e/ou intervenção humana. Agora, tal intervenção acontece à luz de que valores e princípios? Aumentou muito a responsabilidade da vida, pois nem tudo o que é técnica e cientificamente possível de realizar-se é eticamente aceitável. Diante do imperativo tecnológico, do fazer algo novo a qualquer custo, devemos contrapor o imperativo ético, que vai perguntar por que fazer? Entramos, aqui, no amago da discussão ética". (SEHNEM, 2013, p. 127, apud, PESSINI, p.38).
\end{abstract}

Para alguns biólogos há várias posições divergentes quanto ao surgimento da vida humana. Vejamos a aqui três posicionamentos: [...] "A vida tem inicio quando o óvulo e o espermatozoide se fecundam mutuamente". [...] "Outros afirmam que o inicio da existência humana não se dá até que o "produto" da fecundação não estabeleça uma relação alimentícia 
com a mãe - ou seja: até que a "nidação", isto é: quando o óvulo fecundado nas tubas uterinas emigre e se implante no útero, o que começa entre o sexto e o sétimo dia após a concepção. Em outras palavras: até que não tenha alcançado seu lugar, não tem vida humana”.

Porém, para fins deste trabalho, acredita-se que

[...] "O individuo, desde a fecundação, já existe realmente, já possui num ponto pequeno aquilo que um dia se tornará grande. Se ele já é um ser humano quando nasce, e isso todo mundo aceita, ele também o será no primeiro instante da sua vida fetal, porque não há intervalos na transformação que ele sofre e que se estenderá até sua morte”.

Posto isso, entendemos que não existe um consenso, nem para a ciência empírica, pois se trata de algo mais complexo e, portanto, temos muito que caminhar com o auxilio de outros saberes para juntos defendermos a dignidade humana em toda a sua plenitude, desde o nascituro até o termino do seu ciclo de vida, além disso, colocarmos todo o conhecimento a serviço da vida em toda a sua amplitude.

\section{CONSIDERAÇÕES FINAIS:}

Assim concluímos o nosso trabalho de pesquisa que teve como objetivo suscitar três aspectos essências as questões inerentes à vida. Entre elas: a fé e ciência na interdisciplinaridade dos saberes, a prática do aborto e as contribuições da bioética.

A temática sobre a interdisciplinaridade dos saberes reivindica um olhar de aproximação das diversas formas do conhecimento. Essa aproximação não é mais naquela linha de isolamento, nem a recusa antagônica, mas uma perspectiva do respeito às diversas manifestações do conhecimento, como também, dentro de uma postura de nivelamento e contribuição mútua do conhecimento especifico de cada área do saber. Sobretudo entre fé e ciência, que desde o século XVI foi se estabelecendo rupturas e consequentemente o diálogo foi colocado em segundo plano, principalmente nos centros acadêmicos. Entretanto, com os avanços tecnológicos e com as teorias da interdisciplinaridade, entre outras áreas que defendem a interdependência dos saberes, foi possível o reencontro entre a teologia e a ciência.

As contribuições que a pesquisa nos trouxe quanto à prática do aborto no Brasil, são de grande relevância para o levantamento de medidas de intervenções junto aos setores responsáveis por politicas públicas de saúde da mulher. Vejamos aqui três delas: baixa escolaridade; fatores socioeconômicos; falta de informação atrelada ao tabu da sexualidade por parte da família e de outros setores da sociedade.

Junto a tudo isso, faltam as referências básicas sobre o valor a vida como pressupostos norteadores do sentido da existência. E é justamente nesse ponto que devemos refletir com o 
auxílio das diferentes áreas de estudo, entre elas: a filosofia, a teologia e áreas afins; com único propósito de superarmos nossos dilemas em torno do valor e dignidade da pessoa humana.

Por último, as contribuições da bioética, a partir de uma análise das ações antropogênicas, quanto às práticas da manipulação das ciências biológicas. Além, de posicionamentos antagônicos a respeito do inicio da vida. E, por fim, a posição teológica da vida a partir da concepção.

Portanto, somos desafiados a compreendermos a complexidade da vida e a respeitarmos toda manifestação de vida do planeta com seus ciclos de vida e o meio onde ela habita, sobretudo, o homo sapiens, ou seja, a pessoa humana em toda a sua dimensão, a partir da união dos gametas masculinos e femininos até o nascituro.

\section{REFERÊNCIAS BIBLIOGRÁFICAS:}

BRUSTOLIN, Antônio Leomar. Interdisciplinaridade na Teologia: o alargamento da razão no pensamento contemporâneo. Disponível em: http://periodicos.est.edu.br/index.php/estudos_teologicos/article/download/rgor/2249. acesso em:07 de Jun. 2015.

BENTO, Luis Antônio. Bioética: desafios éticos no debate contemporâneo. Ed. São Paulo: Paulinas, 2008, (Coleção ética).

BYK, Christian. Tratado de Bioética/ Christian Byk. - São Paulo: I. ed. Paulus, 2015.

BORTOLANZA e CALGARO. A função da bioética na sociedade de risco. Disponível em: $<$ http://www.ambito-

juridico.com.br/site/index.php?artigo_id=8293\&n_link=revista_artigos_leitura $>$ acesso em: o6 de Jun. 2015.

BRAGA et al. Aborto "uma consequência da gravidez na adolescência." Disponível em :http://www.faculdadedofuturo.edu.br/revista/2008/pdfs/REMAS 3 (I) 76 a88.pdf >acesso em: 27 de abril 2017.

BÍBLIA, N. T.(Lc 1,39-44). Maria visita Izabel. In BÍBLIA. SAGRADA BIBLIA: tradução Frei José ofm. São Paulo, SP - BRASIL. Editora Ave Maria Ltda. 1987.p.1346.

DÉBORA e DINIZ. Bioética e aborto. Disponível em: http://www.portalmedico.org.br/biblioteca_virtual/bioetica/ParteIIIaborto.htm>acesso em: 28 de abril 2017.

FORTES, Corrêa Clarisse. UFSM. Interdisciplinaridade, Origem, Conceito e Valor. Disponível em: http://www.pos.ajes.edu.br/arquivos/referencial_20120517101727.pdf>acesso em: 27 de abril 2017. 
IONE, Aguiar. Veja onde se faz mais aborto no Brasil, de acordo com o IBGE. Extraído de: http://agenciapatriciagalvao.org.br/direitos-sexuais-e-reprodutivos/veja-onde-se-faz-maisaborto-no-brasil-de-acordo-com-o-ibge/acesso em: 27 de Abril 2017.

MIRANDA, Gonzalo. Bioética e eutanásia/ Gonzalo Miranda; Tradução Elaine Caramella Bauru, SP: EDUSC, 1998.

OLIVEIRA, Fátima. Bioética: uma face da cidadania/ Fatima Oliveira - 2. Ed. reform - São Paulo: Moderna, 20I4.

PESSINI, Leocir. Problemas atuais de Bioética/ Leocir Pessini, Christian de Paul Barchifontaine. - 8. ed. revista ampliada. - São Paulo: Centro Universitário São Camilo: Loyola, 2007. 584p.

PESSINI, Leocir. Fundamentos da Bioética/ Leocir Pessini, Christian de Paul Barchifontaine. Ed. Paulus, 1996.

SANCHES, Mário Antonio. Diálogo entre Teologia e Ciências Naturais. O mundo da Saúde, ano 31, v. 3I, n. 2, abri/Jun, 2007. São Paulo: São Camilo, 179-186.

SANCHES, Mário Antônio et al. A dignidade do embrião humano: diálogo entre teologia e bioética. São Paulo: Editora Ave-Maria, 2012.

SEHNEM, Antônio Marino. Bioética. Batatais, SP: Claretiano, 2013. 174 p.

ZILES, Urbano. Desafios atuais para a Teologia/ Urbano Ziles. - São Paulo: Paulus, 2orr. (Coleção Teologia hoje). 